\title{
Music performance anxiety: New insights from young musicians
}

\author{
Dianna T. Kenny and Margaret S. Osborne
}

Australian Centre for Applied Research in Music Performance, Conservatorium of Music, The University of Sydney

Received 20.10.2005

Accepted 17.01.2006

\section{Keywords}

music performance anxiety, young musicians, assessment, cognition

\section{ABSTRACT}

Music performance anxiety (MPA) is a relatively neglected psychological phenomenon that rarely appears in mainstream psychological journals or textbooks. To date, this field of inquiry has focused primarily on professional and amateur adult musicians or college level music students. With the exception of a small number of recent additions to the literature, there have been few studies examining the experience of MPA in younger musicians. In this paper, we review our work on MPA in general, and summarize our recent work with young musicians. We argue that the experience of MPA may begin early in a musical career and that the characteristics of this experience are qualitatively similar to those experienced by adult musicians. There are therefore compelling reasons to address MPA early and to take a strong preventive focus on a condition that to date shows persistence over time and only modest response to available treatments.

\section{INTRODUCTION}

Performance anxiety is a group of disorders that affect individuals in a range of endeavors, from test-taking (Elliott \& McGregor, 1999), maths performance (Ashcraft \& Faust, 1994), public speaking (Merritt, Richards \& Davis, 2001), sport (Hall \& Kerr, 1998; Hanton, Mellalieu, \& Hall, 2002) and the performing arts in dance (Tamborrino, 2001), acting (Wilson, 2002) and music (Deen, 2000; Ryan, 2003). Females are two to three times more likely to experience anxiety than males (American Psychiatric Association, 1994; Lewinsohn, Gotlib, Lewinsohn, Seeley \& Allen, 1998) and this relationship appears to hold for music performance anxiety (MPA) where studies demonstrate that females have significantly higher MPA than males (Huston, 2001; Osborne \& Franklin, 2002; Sinden, 1999), although this relationship is more complex in children (Ryan, 2003).

Very young children rarely experience the type of performance anxiety that afflicts older people. On the contrary, most young children love to perform, love an audience and seem blissfully unaware of any flaws in their "performance." How do many of us undergo the transition from "Mummy, look at me, aren't I clever?" to "Please don't ask me to perform; I know that I will make a mess of it and embarrass myself." This transition is due to a combination of factors, the most important of which are our innate temperament; trait anxiety; increasing cognitive capacity, self-reflective function and capacity for perspective taking that develop through childhood and adolescence; the type of parenting and other interpersonal experiences that we have; our perception and interpretation of the world around us; technical skill and mastery, and specific performance experiences that may have positive or negative outcomes.

Nagel (1987) found that $90 \%$ of adult musicians began their musical instruction before the age of 12 ,

Correspondence concerning this article should be addressed to Dianna T Kenny PhD, Director, Australian Centre for Applied Research in Music Performance, Sydney Conservatorium of Music, The University of Sydney, NSW, Australia. E-mail: D.Kenny@fhs.usyd.edu.au 
$46 \%$ of these before the age of seven. Despite the early commencement of musical training, little attention has been paid to MPA in children, although several studies have acknowledged that children experience anxiety in other performance-evaluative contexts such as sport and test taking (see Fleege, Charlesworth, Burts \& Hart, 1992; Hembree, 1988; Kass \& Gish, 1991; Passer, 1983; Scanlan \& Lewthwaite, 1984; Simon \& Martens, 1979; Smith, Smoll \& Barnett, 1995; Terry, Coakley \& Karageorghis, 1995; Zatz \& Chassin, 1985). The presence of MPA in children was first identified incidentally by Simon and Martens (1979), whose study's main focus was sports performance anxiety. In the course of their study of 749 9-14 year old boys that compared anxiety in test, sport and musical activities, the greatest anxiety was reported by boys performing solo on a musical instrument. Performing with a band was responsible for the highest anxiety among group activities, including team sports. Recently, Ryan (1998, 2004) assessed the prevalence and symptoms of MPA in child musicians, and found that many children display similar constellations of physiological symptoms of MPA as adult musicians and that performance anxiety was negatively correlated with self-esteem and performance quality. MPA experience in child musicians has also been shown to increase with audience size and perceived importance of the performance (LeBlanc et al, 1997), a relationship also frequently observed in research with adult musicians. Ryan (2005) was the first to examine MPA in children. She assessed performance anxiety in 173 children in grades three through seven. Children completed the trait and state form of the State-Trait Anxiety Inventory for Children during a regular school day and the state form again on the day of a major school concert. Results indicated that state anxiety was significantly higher on the day of the school concert and was related to children's level of trait anxiety. This study provided compelling evidence that MPA certainly exists in children, and may share characteristics with its manifestation in adults.

Barlow's (2000) model of anxiety is useful in aiding our understanding of performance anxiety in general and MPA in particular. His model proposes an integrated set of triple vulnerabilities that can account for the development of an anxiety or mood disorder. These are a:

I. generalized biological (heritable) vulnerability;

II. generalized psychological vulnerability based on early experiences in developing a sense of control over salient events, and a

III. more specific psychological vulnerability whereby anxiety comes to be associat ed with certain envi- ronmental stimuli through learning processes such as respondent or vicarious conditioning.

Barlow argues that genetic predisposition and sensitizing early life experiences may be sufficient to produce a generalized anxiety or mood (depression) disorder. However, the third set of vulnerabilities appears necessary to produce focal or specific anxiety disorders such as panic disorder or specific phobias. For example, social evaluation may be accompanied by heightened somatic sensations that become associated with a perceived increase in threat or danger. In the case of young performers who are high in trait anxiety (the expression of the generalized biological vulnerability), who come from home environments in which expectations for excellence are high but support for achieving excellence is low (generalized psychological vulnerability), exposure to early and frequent evaluations and self-evaluations of their performances in a competitive environment (specific psychological vulnerability) may be sufficient to trigger the physiological, behavioral and cognitive responses characteristic of MPA. Anxiety may be triggered by conscious, rational concerns or by cues that trigger, unconsciously, earlier anxiety producing experiences or somatic sensations. These may include earlier aversive performance incidents that may form the basis of the subsequent development of negative cognitions (Beck, 1995; Beck, Emery \& Greenberg, 1985; Barlow, 2002). Once triggered, the person shifts into a selfevaluative attention state, in which self-eva- luation of perceived inadequate capabilities to deal with the threat, in this case, the imminent performance, is prominent. The attention typically narrows to a focus on catastrophic cognitive self-statements that disrupt concentration and performance. In this respect, MPA may share commonalities with social anxiety and in its extreme form appears similar to social phobia. One could argue that the conditions under which one performs, that is, the degree of social evaluative threat perceived by the performer is the defining feature of social phobia. Those perceiving most threat are likely to experience the greatest anxiety, and those who are most anxious are more likely to perceive performance conditions as more threatening.

\section{Testing the application of Barlow's theory to MPA}

The Kenny Music Performance Anxiety Inventory (K-MPAI) (Kenny et al., 2004) was developed to assess the relevance to MPA of the emotion-based theory of anxiety proposed by Barlow (2000). Items for the inventory 


\section{Table 1.}

Kenny Music Performance Anxiety Inventory (K-MPAI)

Below are some statements about how you feel generally and how you feel before or during a performance. Please circle one number to indicate how much you agree or disagree with each statement.

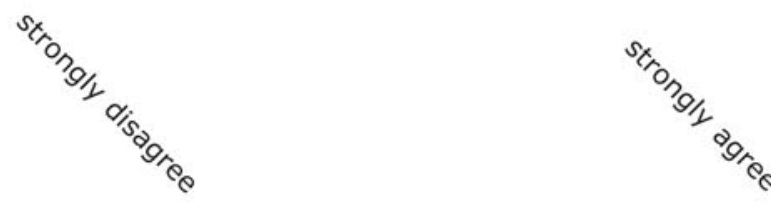

1 Sometimes I feel depressed without knowing why

2 I find it easy to trust others

3 I rarely feel in control of my life

4 I often find it difficult to work up the energy to do things

5 Excessive worrying is a characteristic of my family

6 I often feel that life has not much to offer me

7 The harder I work in preparation for a concert, the more likely I am to make a serious mistake

8 I find it difficult to depend on others

9 My parents were mostly responsive to my needs

10 I never know before a concert whether I will perform well

11 I often feel that I am not worth much as a person

12 During a performance I find myself thinking about whether I'll even get through it

13 Thinking about the evaluation I may get interferes with my performance

14 Even in the most stressful performance situations, I am confident that I will perform well

15 I am often concerned about a negative reaction from the audience

16 Sometimes I feel anxious for no particular reason

17 From the beginning of my music studies, I remember being anxious about performing

18 I worry that one bad performance will ruin my career

19 My parents almost always listened to me

20 I give up worthwhile performance opportunities due to anxiety

21 As a child, I often felt sad

22 I often prepare for a concert with a sense of dread and impending disaster

23 I often feel that I have nothing to look forward to

24 My parents encouraged me to try new things

25 I worry so much before a performance, I cannot sleep

26 My memory is usually very reliable

\begin{tabular}{|c|c|c|c|c|c|c|}
\hline-3 & -2 & -1 & 0 & 1 & 2 & 3 \\
\hline 3 & 2 & 1 & 0 & -1 & -2 & -3 \\
\hline-3 & -2 & -1 & 0 & 1 & 2 & 3 \\
\hline-3 & -2 & -1 & 0 & 1 & 2 & 3 \\
\hline-3 & -2 & -1 & 0 & 1 & 2 & 3 \\
\hline-3 & -2 & -1 & 0 & 1 & 2 & 3 \\
\hline-3 & -2 & -1 & 0 & 1 & 2 & 3 \\
\hline-3 & -2 & -1 & 0 & 1 & 2 & J \\
\hline 3 & 2 & 1 & 0 & -1 & -2 & -3 \\
\hline-3 & -2 & -1 & 0 & 1 & 2 & 3 \\
\hline-3 & -2 & -1 & 0 & 1 & 2 & 3 \\
\hline-3 & -2 & -1 & 0 & 1 & 2 & 3 \\
\hline-3 & -2 & -1 & 0 & 1 & 2 & 3 \\
\hline 3 & 2 & 1 & 0 & -1 & -2 & -3 \\
\hline-3 & -2 & -1 & 0 & 1 & 2 & 3 \\
\hline-3 & -2 & -1 & 0 & 1 & 2 & 3 \\
\hline-3 & -2 & -1 & 0 & 1 & 2 & 3 \\
\hline-3 & -2 & -1 & 0 & 1 & 2 & 3 \\
\hline 3 & 2 & 1 & 0 & -1 & -2 & -3 \\
\hline-3 & -2 & -1 & 0 & 1 & 2 & 3 \\
\hline-3 & -2 & -1 & 0 & 1 & 2 & 3 \\
\hline-3 & -2 & -1 & 0 & 1 & 2 & 3 \\
\hline-3 & -2 & -1 & 0 & 1 & 2 & 3 \\
\hline 3 & 2 & 1 & 0 & -1 & -2 & -3 \\
\hline-3 & -2 & -1 & 0 & 1 & 2 & 3 \\
\hline 3 & 2 & 1 & 0 & -1 & -2 & -3 \\
\hline
\end{tabular}

were either specially constructed or selected from other scales to address each of Barlow's theoretical components, including evocation of anxious propositions (e.g. uncontrollability, unpredictability, negative affect, situational cues); attentional shift (e.g. task or self-evaluative focus, fear of negative evaluation); physiological arousal and memory bias. Questions are answered on a 7-point Likert scale ranging from "-3: Strongly disagree" to "+3: Strongly agree". The maximum score is 156 , with higher scores indicating greater anxiety and psychological distress. The KMPAI is presented in Table 1.
The scale was tested using professional choral artists who were members of a national opera company. Scores for the K-MPAI scale were significantly positively correlated with both sub-scales of the State Trait Anxiety Inventory (STAI) (Spielberger, 1983), the standard research measure used to assess state and trait anxiety, and the Cox and Kenardy Music Performance Anxiety (CK-MPA) inventory that was modified for this study. Two versions were created, one for solo performance and one for choral performance. The K-MPAI also demonstrated excellent internal reliability (Cronbach's alpha $=.94$ ) (Kenny et al., 
2004). Regression analyses indicated that the trait scale of the STAI and the solo scale of the CK-MPA were the only independent predictors of KMPAI; these two variables accounted for $85.3 \%$ of the variance in K-MPAI scores. This scale therefore shows much promise as both a predictor of MPA and as an outcome measure following treatment for MPA. Further replications of the findings are required before it can be recommended for use in clinical or educational settings.

\section{MEASUREMENT OF MPA IN ADOLESCENT MUSICIANS}

The empirical investigation of MPA in adolescents has received little attention to date and no measures specifically assessing MPA in adolescents have been empirically validated. To redress this situation, we developed the Music Performance Anxiety Inventory for Adolescents (MPAI-A) (Osborne \& Kenny, 2005a). Data from 381 young musicians aged 12 to 19 years attending secondary high schools specializing in the performing arts were used to investigate the factor structure, internal reliability, construct and divergent validity of the MPAI-A. Table 2 presents the 15 items comprising the MPAI-A.

Examination of both the number of eigenvalues greater than one and the factor loadings supported a decision to treat the scales as multi-dimensional, although the first factor accounted for most of the variance. Using a best-fit solution, the factor analysis identified three eigenvalues greater than one, which together accounted for $53 \%$ of the variance. The first factor, Somatic and Cognitive Features, accounted for $43 \%$ of the variance. The majority of items loading on this factor consisted of those describing the physical manifestations of performance anxiety immediately prior to and during a performance. Two items related to worry and fear of making mistakes. The second factor, Performance Context, accounted for $6 \%$ of the variance, and described the preference performers have for either solo or group contexts and the nature of the audience. The third factor, Performance Evaluation, contained items relating to the evaluation that both the audience and performer may make of a performance, the consequences stemming from these evaluations (particularly when a mistake is made), and difficulty concentrating in front of an audience when performing. This factor accounted for an additional 3\% of the variance. A revised scale will include a couple of items on performing from memory, as this is becoming a standard expectation of performance, even for young children.
Cronbach's alpha for the full measure was .91 and for the three separate scales as follows: .9 for somatic and cognitive features; .77 for performance context; .69 for performance evaluation. Construct validity was demonstrated by significant positive relationships with social phobia (measured using the Social Phobia Anxiety Inventory, Beidel, Turner \& Morris, 1995; 1998) and trait anxiety (measured using the State Trait Anxiety Inventory, Speilberger, 1983). The MPAI-A demonstrated convergent validity via moderate to strong positive correlations with the adult measure of MPA: Kenny Music Performance Anxiety Inventory (K-MPAI) (Kenny et al., 2004), described above. Because no other child or adolescent MPA measures exist, this scale was included to test the convergent validity of the MPAI-A. Discriminant validity for the MPAI-A was established by a weaker positive relationship with depression, and no relationship with externalizing behaviour problems.

Girls scored significantly higher than boys $[t(296)=-3.59, p<.001]$ on the MPAI-A and the means by grade showed a curvilinear trend, with a rise from grade 8 that peaked at grade 10, thereafter declining to pre-grade 8 levels. These findings were consistent with other research showing that levels of MPA are generally higher in women than men (Huston, 2001; Steiner, 1998), although Ryan (2003) found a differential pattern of anxious responding in boys and girls. Girls had substantially higher heart rates than boys immediately prior to but not during their performance. Boys had significantly more anxious behaviors than girls both prior to, and during a performance. Social/interpersonal anxiety increases for males and females as peers become the increasing focus of attention (Kashani et al., 1989) with girls displaying significantly greater fear of performing in front of others (Essau et al., 1999). The curvilinear trend in MPA levels is consistent with the development of formal operational thought, a characteristic cognitive change associated with the progression from childhood to adolescence (Piaget, 1970). These changes include an increase in retrospection and self-evaluation. Formal operational thought tends to develop in areas in which the adolescent is greatly interested and involved. The cognitive skill of formal operations allows adolescents to imagine other people's thoughts, which can lead some to mistakenly believe that others are as preoccupied with their thoughts and appearance as the adolescents themselves. This can create anxiety and self-criticism in some adolescents (Kenny, 2000). Adolescence is also characterized by a decreased satisfaction with family, which leads to peers becoming the 
Table 2.

Music Performance Anxiety Inventory (MPAI-A)

\begin{tabular}{|c|c|c|c|c|c|c|c|c|}
\hline \multirow[b]{2}{*}{1} & \multirow[b]{2}{*}{${ }^{1}$ Before I perform, I get butterflies in my stomach } & \multicolumn{2}{|c|}{$\begin{array}{l}\text { None } \\
\text { of the time }\end{array}$} & \multicolumn{3}{|c|}{$\begin{array}{l}\text { About half } \\
\text { the time }\end{array}$} & \multicolumn{2}{|c|}{$\begin{array}{l}\text { All of } \\
\text { the time }\end{array}$} \\
\hline & & 0 & 1 & 2 & 3 & 4 & 5 & 6 \\
\hline 2 & ${ }^{1}$ I often worry about my ability to perform & 0 & 1 & 2 & 3 & 4 & 5 & 6 \\
\hline 3 & ${ }^{2}$ I would rather play on my own, than in front of other people & 0 & 1 & 2 & 3 & 4 & 5 & 6 \\
\hline 4 & ${ }^{1}$ Before I perform, I tremble or shake & 0 & 1 & 2 & 3 & 4 & 5 & 6 \\
\hline 5 & ${ }^{1}$ When I perform in front of an audience, & & & & & & & \\
\hline & I am afraid of making mistakes & 0 & 1 & 2 & 3 & 4 & 5 & 6 \\
\hline 6 & $\begin{array}{l}\text { 'When I perform in front of an audience, } \\
\text { my heart beats very fast }\end{array}$ & 0 & 1 & 2 & 3 & 4 & 5 & 6 \\
\hline 7 & $\begin{array}{l}{ }^{3} \text { When I perform in front of an audience, } \\
\text { I find it hard to concentrate on my music }\end{array}$ & 0 & 1 & 2 & 3 & 4 & 5 & 6 \\
\hline 8 & ${ }^{3}$ If I make a mistake during a performance, I usually panic & 0 & 1 & 2 & 3 & 4 & 5 & 6 \\
\hline 9 & ${ }^{1}$ When I perform in front of an audience I get sweaty hands & 0 & 1 & 2 & 3 & 4 & 5 & 6 \\
\hline & $\begin{array}{l}{ }^{3} \text { When I finish performing, I usually feel happy } \\
\text { with my performance }\end{array}$ & 0 & 1 & 2 & 3 & 4 & 5 & 6 \\
\hline 11 & ${ }^{2}$ I try to avoid playing on my own at a school concert & 0 & 1 & 2 & 3 & 4 & 5 & 6 \\
\hline 12 & ' ${ }^{1} J u s t$ before I perform, I feel nervous & 0 & 1 & 2 & 3 & 4 & 5 & 6 \\
\hline & $\begin{array}{l}{ }^{3} \text { I worry that my parents or teacher might not like } \\
\text { my performance }\end{array}$ & 0 & 1 & 2 & 3 & 4 & 5 & 6 \\
\hline 14 & ${ }^{2}$ I would rather play in a group or ensemble, than on my own & 0 & 1 & 2 & 3 & 4 & 5 & 6 \\
\hline 15 & ${ }^{1}$ My muscles feel tense when I perform & 0 & 1 & 2 & 3 & 4 & 5 & 6 \\
\hline
\end{tabular}

$1=$ Somatic and cognitive features

${ }^{2}=$ Performance context

${ }^{3}=$ Performance evaluation

focus of attention and increased social/interpersonal anxiety (Kashani et al., 1989). Given that adolescents are also more likely to evaluate themselves in terms of academic and other achievements (Heaven, 2001), the increasing levels of MPA with age in the junior high school years is consistent with other research findings in the area. The greater the commitment to music, the greater will be the expectation from self and others regarding performance standard and quality.

Osborne and Kenny (2005a) also found that MPA was more specifically related to social anxiety than trait anxiety with stronger positive correlations between the MPAI-A and social phobia measures than MPAI-A and trait anxiety. Results on the Social Phobia Anxiety Inventory for Children (SPAI-C; Beidel et al., 1998) indicated potentially higher rates of social phobia diagnosis (between $6 \%$ and $21 \%$ ) than those found in most adolescent community samples (between $1 \%$ and $2 \%$ ) (Anderson, Williams, McGee, \& Silva, 1987; Essau, Conradt, \& Petermann, 1999; Kashani \& Orvaschel, 1990; Maroon, 2003).

To extend the use of the MPAI-A with students of a different demographic, Osborne, Kenny and Holsomback (2005) investigated the psychometric properties of the MPAI-A with younger band musicians aged
11-13 years from Texas, USA and these findings were compared to the original sample drawn from Sydney, Australia. The results demonstrated that the MPAI-A was a psychometrically robust measure, with the same high internal consistency ( $a=.91$ ) achieved with the same 15 items in this validation sample. Further support for the validity of the MPAI-A was shown by the significant differences in levels of MPA according to musical ability. American students who were less advanced in their musical training reported significantly lower MPA on the MPAI-A than the 11-13 year old Sydney group, a more highly trained group of musicians. The MPAI-A reliably discriminated levels of MPA according to the musical skill of the performers in both the Australian and American samples. Students with less musical training, who engaged in less technically demanding performances scored significantly lower on the MPAI-A than the more highly trained musicians of the same age. Another interesting finding from this study was that students in both samples who reported that they wanted to be a professional musician had lower MPA scores compared to those who indicated "No" or "Don't know." It is possible that students reject or are uncertain of a career as a professional musician because of the discomfort associated with high MPA. 
Alternatively, it is possible that students with professional career goals are better performers and have greater expectations of success. This finding is worthy of further investigation. As predicted, girls scored higher on the MPAI-A than boys; and those in the age group 14-19 showed the highest levels of MPA of the three age groups assessed.

The MPAI-A, the first empirically validated measure of adolescent musicians' performance anxiety will hopefully enhance and promote phenomenological and treatment research. The field is now poised to develop and evaluate appropriate preventive, management and treatment strategies for anxious adolescent musicians.

\section{Role of cognitions, autonomic arousal and behaviour}

In the music research literature, MPA is commonly viewed as a constellation of three interactive yet partially independent factors: cognitions, autonomic arousal, and overt behavioral responses (Craske \& Craig, 1984; Lederman, 1999; Salmon, 1990). There is empirical support for this three-factor model of MPA. Craske and Craig (1984) demonstrated greater response synchrony among high trait, compared to low trait anxious performers, particularly when performing in a stressful situation involving evaluation of their performances by expert judges. Low anxious individuals experienced elevated heart rate but not cognitive or behavioral symptoms in the performance condition when compared to a "warm-up" baseline condition in contrast to high anxious individuals who experienced elevations in all three areas. High levels of self-reported performance anx-iety were also related to lower levels of confidence.

However, researchers are in dispute regarding the nature of this interaction. Zinn, McCain and Zinn (2000) argue that performance anxiety is primarily a psycho physiological event in which the autonomic nervous system initiates and maintains MPA. Alternatively, Kirchner (2003) maintains the symptomatic aspects of MPA are activated by the perception of threat by the performer, and not the autonomic nervous system. Wilson (2002) describes threat perception as an interaction of three variables that play important roles in the experience of distressing anxiety: the performer's constitutional and learned tendency to become anxious in response to situations of social stress (trait anxiety); the degree of task mastery, and the degree of situational stress, where high anxiety is more likely to be experienced in situations where social or environmental pressures are high.
Negative cognitions may have a more important role in causing performance disruption than physiological or behavioral components of anxiety (Bruce \& Barlow, 1990). In MPA, arousal appears to be subject to cognitive appraisals that determine the subsequent emotional response, and may or may not optimize performance, depending on how it is interpreted by the performer (Cleaver, 1997; Salmon, 1990). Although Craske and Craig (1984) found that neither the behavioral, physiological or cognitive systems uniquely defined the MPA state, particular cognitive styles contributed strongly to anxiety maintenance, and are capable of precluding the extinction of anxiety despite non-reinforced feared stimulus exposure (Borkovec, 1976). Most and least anxious performers differ in their fear of negative audience reactions, as well as in their awareness of poor preparation and poor performance. Musicians with high MPA show higher fear of negative evaluation than low MPA musicians (Wolfe, 1989). In another study, the two most critical cognitions predicting MPA in solo music performances related to the consequences (e.g., "My career is ruined", "If I make the slightest mistake, they'll think I'm incompetent and I'll get thrown out of school") and likelihood of negative evaluation (e.g., "The audience expects me to play at a higher standard than I can play, and they'll be disappointed in me") (Osborne \& Franklin, 2002). On the other hand, musicians who are able to control their MPA at moderate levels do so by using realistic self-appraisal, eg. "I'm bound to make a few mistakes, but so does everyone".

These findings formed the basis for the development of two hypotheses tested in a recent study (Osborne \& Kenny, 2005b): first, that music students who reported a negative music performance experience would self-report higher levels of MPA than those who had not had previous negative performance experience; and second, that negative cognitions would be more predictive of adolescent MPA than the somatic and emotional components of this sensitizing experience. Two hundred and ninety eight music students from high schools specializing in the performing arts were asked to provide written descriptions of their worst performance experience, what happened and how they felt, specifying their age at the time, audience members, and any events that occurred subsequent to the performance. Descriptions were classified according to six domains: situational and behavioral factors, affective, cognitive and somatic symptoms of anxiety, and outcome. Accounts were scored in each domain and a total score was calculated. Scores were summed to provide a linear scale that was compared to self-report MPA, measured using the Music Performance 


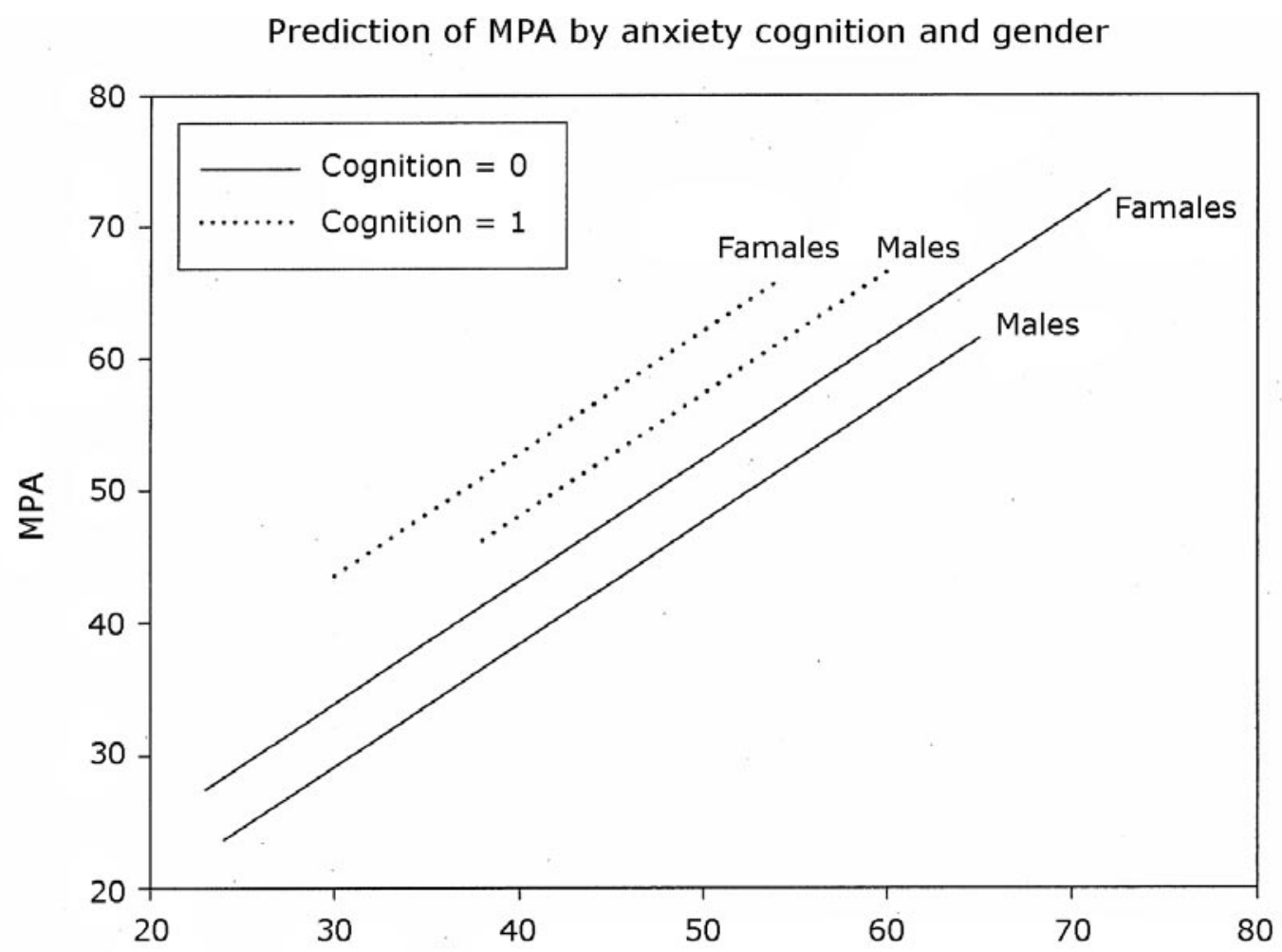

Figure 1.

Anxiety scale

Prediction of MPA by anxiety, cognition and gender

Anxiety Inventory for Adolescents, (Osborne \& Kenny, 2005b) and standardized trait anxiety scores, measured using the STAI.

This study used a methodology similar to Ryan (2003) of open ended questions, in which participants were asked to generate their own statements about their performance experience rather than respond to statements on questionnaires. In this way, we were able to access spontaneous cognitions of young musicians to ascertain whether they developed the same types of anxious cognitions as those typically observed in anxious adults. Results indicated that MPA was best predicted by trait anxiety and gender, and that the presence of negative cognitions in their worst experience account improved the prediction of MPA over trait anxiety and gender alone. Females reported more emotional distress than males and had significantly higher total scores. These findings confirm patterns found in adult performers and across other forms of performance anxiety in children (e.g. test anxiety). Ryan (1999) also found gender differences in eighth and ninth grade music students, with females reporting more anxiety than males. This study highlighted cognitions as an important element to address in the treatment of MPA in young musicians. Figure 1 summarizes the degree to which the presence of negative cognitions about a poor performance experience adds to the prediction of MPA for both males and females. The number of negative cognitions (eg "I was very worried about the performance"; "my teacher had very high expectations of me"; "I worried that my teacher would be disappointed in me;" "the examiners were very intimidating and psyched me out") spontaneously produced in the worst experience description were counted. In figure 1 , cognition is presented as a binary variable coded 0 for those producing $0-1$ negative cognitions and 1 for those producing two or more negative cognitions in their account of their worst performance experience. Both MPAI-A and STAI-T scores are in their original units.

\section{The role of perfectionism in performance anxiety}

Music performance requires a high level of skill in a diverse range of skill areas including fine motor dexterity and co-ordination, attention and memory, aesthetic and interpretative skills. To achieve prominence 
requires the attainment of near perfection demanding years of training, solitary practice, and constant, intense self-evaluation. Barlow's (2000, p. 1249) definition of anxiety, which incorporates a "sense of uncontrollability...a state of helplessness...because one is unable to obtain desired results or outcomes..." has much in common with the definition of perfectionism given by Frost, Marten, Lahart, and Rosenblate (1990, p. 449) i.e. "excessive concern over making mistakes, high personal standards, perception of high parental expectations and high parental criticism, the doubting of the quality of one's actions, and a preference for order and organization". Perfectionism as a personality trait has been poorly evaluated in musicians. Mor, Day, Flett and Hewitt (1995) investigated this trait in 49 professional classical musicians and found that performers with higher personal standards of perfection (eg. "I must work to my full potential at all times") and social standards of perfection (eg. "The people around me expect me to succeed at everything I do") experienced more debilitating anxiety than those performers who did not score highly on these items. Another study that assessed the Frost Perfectionism Scale on a sample of 138 university instrumental music students reported a significant relationship between dimensions of perfectionism (high concern over mistakes, high doubts about actions and low personal standards) and performance anxiety (Sinden, 1999). In a subsequent study, Kawamura et al (2001) found that maladaptive perfectionism was related to a social/trait anxiety/ worry factor.

One would expect that for elite performers, there would be a close relationship between anxiety and perfectionism. Indeed, in the study of operatic chorus artists described earlier, Kenny, Davis \& Oates (2004) found that perfectionism was associated with trait anxiety and MPA. Although perfectionism was highly correlated with the Kenny-Music Performance Anxiety Inventory ( $K-M P A I)$, it did not add to the prediction of $\mathrm{K}$-MPAI in the regression analysis after the influence of state and trait anxiety, and solo and choral musical performance anxiety were considered.

In our study of adolescent musicians, we examined the relationship between perfectionism, using the Frost Perfectionism Scale and MPA using the MPAI-A. While the original scale consists of six subscales: Concern over Mistakes, Personal Standards, Parental Expectations, Doubts about Actions, and Organization, for our sample, factor analysis produced two factors - a general perfectionism factor (15 items) and a need for neatness and organization scale ( 3 items) which together accounted for $37 \%$ of the total variance. The total perfectionism scale correlated significantly with the total MPAI-A $(r=.213, p<.001)$ but was a poor predictor of MPA. Further investigation of the role of perfectionism in the development and maintenance of MPA in adolescent musicians is required.

\section{CONCLUSIONS}

Recent advances in the theorizing and measurement of MPA in children and adolescents have increased our understanding of this experience for young musicians. However, we still do not have a good understanding of how the condition develops, under what conditions and in which perfor-mer. Longitudinal studies are needed to answer these aetiological questions, as are treatment outcome studies to determine how best to assist young musicians whose performance and career prospects are impaired by this disabling condition.

\section{References}

American Psychiatric Association. (1994). Diagnostic and Statistical Manual of Mental Disorders (4th ed.). Washington, DC: American Psychiatric Association.

Anderson, J., Williams, S., McGee, R., \& Silva, P. A. (1987). DSM-III disorders in preadolescent children: Prevalence in a large sample from the general population. Archives of General Psychiatry, 69-76. Www

Ashcraft, M.H., \& Faust, M.W. (1994). Mathematics anxiety and mental arithmetic performance: An exploratory investigation. Cognition and Emotion, 8, 97-125.

Barlow, D. (2000). Unravelling the mysteries of anxiety and its disorders from the perspective of emotion theory. American Psychologist, 55, 1247-1263.

Barlow, D. H. (2002). Anxiety and its disorders: The nature and treatment of anxiety and panic (2nd ed.). New York: Guilford Press.

Beck, Aaron T. Cognitive therapy: Past, present, and future. (1995). In Mahoney, Michael J (Ed.) Cognitive and constructive psychotherapies: Theory, research, and practice. (pp. 29-40). New York, NY, US: Springer Publishing Co.

Beck, A. T., Emery, G., \& Greenberg, R. (1985). Anxiety disorders and phobias: A common perspective. New York: Basic.

Beidel, D. C., Turner, S. M., \& Morris, T. L. (1995). A new inventory to assess childhood social anxiety and phobia: The Social Phobia and Anxiety Inventory for Children. Psychological Assessment, 7, 73-79.

Beidel, D. C., Turner, S. M., \& Morris, T. L. (1998). Social Phobia and Anxiety Inventory for Children 
(SPAI-C). North Tonawanda, New York: Multi-Health Systems Inc.

Bruce, T. J., \& Barlow, D. H. (1990). The nature and role of performance anxiety in sexual dysfunction. In H. Leitenberg (Ed.). Handbook of social and evaluation anxiety (pp. 357-384). New York: Plenum.

Borkovec, T. (1976). Physiological and cognitive processes in the regulation of anxiety. In G. E. Schwartz \& S. Shapiro (Eds.), Consciousness and Self-Regulation: Vol. 1 (pp. 261-312). New York: Plenum Press.

Cleaver, D. (1997). Alleviating musical performance anxiety using Neuro-Linguistic Programming based techniques: an investigation. Unpublished BME (Hons) Thesis, University of Sydney, Sydney.

Craske, M., \& Craig, K. (1984). Musical-performance anxiety: The three-systems model and self-efficacy theory. Behavior Research and Therapy, 22, 267-280. $\underline{W w}$

Deen, D.R. (2000). Awareness and breathin: Keys to the moderation of musical performance anxiety. Dissertation Abstracts International, 60, 4241.

Elliot, A. J \& McGregor, H.A. (1999). Test anxiety and the hierarchical model of approach and avoidance achievement motivation. Journal of Personality \& Social Psychology, 76, 628-644. Www

Essau, C. A., Conradt, J., \& Petermann, F. (1999). Frequency and comorbidity of social phobia and social fears in adolescents. Behaviour Research and Therapy, 37, 831-843. Www

Fleege, P. O., Charlesworth, R., Burts, D. C., \& Hart, C. H. (1992). Stress begins in kindergarten: A look at behavior during standardized testing. Journal of Research in Childhood Education 7, 20-26.

Frost, R., Marten, P., Lahart, C., \& Rosenblate, R. (1990). The dimensions of perfectionism. Cognitive Therapy and Research, 14, 449-468.

Hall, H. K., \& Kerr, A. W. (1998). Predicting achievement anxiety: A social-cognitive perspective. Journal of Sport and Exercise Psychology, 20, 98-111.

Hanton, S., Mellalieu, S.D., \& Hall, R. (2002). Re-examining the competitive anxiety trait-state relationship. Personality and Individual Differences, 33, 1125-1136.

Heaven, P. C. L. (2001). The social psychology of adolescence. Hampshire, UK: Palgrave.

Hembree, R. (1988). Correlates, causes, effects, and treatment of test anxiety. Review of Educational Research 58, 47-77.

Huston, J. L. (2001). Familial antecedents of musical performance anxiety: A comparison with social anxi- ety. Dissertation Abstracts International: Section B: the Sciences \& Engineering, 62, 551.

Kashani, J. H., \& Orvaschel, H. (1990). A community study of anxiety in children and adolescents. American Journal of Psychiatry, 147, 313-318. www Kashani, J. H., Orvaschel, H., Rosenberg, T. K., \& Reid, J. C. (1989). Psychopathology in a community sample of children and adolescents. Journal of the American Academy of Child and Adolescent Psychiatry, 28, 701-706. |WwW|

Kass, R. G., \& Gish, J. M. (1991). Positive reframing and the test performance of test anxious children. Psychology in the Schools, 28, 43-52.

Kawamura, K.Y., Hunt, S. L., Frost, R. O., \& DiBartoIo, P. M. (2001). Perfectionism, Anxiety, and Depression: Are the Relationships Independent? Cognitive Therapy and Research, 25, 291-301.

Kenny, D. T. (2000). Psychological foundations of stress and coping: A developmental perspective. In D. T. Kenny, J. G. Carlson, F. J. McGuigan \& J. L. Sheppard (Eds.), Stress and health: Research and clinical applications (pp. 467). Amsterdam: Gordon Breach/Harwood Academic Publishers.

Kenny, D. T., Davis, P. J., \& Oates, J. (2004). Music performance anxiety and occupational stress amongst opera chorus artists and their relationship with state and trait anxiety and perfectionism. Journal of Anxiety Disorders, 18, 757-777. WwW

Kirchner, J. M. (2003). A qualitative inquiry into musical performance anxiety. Medical Problems of Performing Artists, 18, 78-82.

LeBlanc, A., Jin, Y. C., Obert, M., \& Siivola, C. (1997). Effect of audience on music performance anxiety. Journal of Research in Music Education 45, 480$-496$.

Lederman, R. J. (1999) Medical treatment of performance anxiety: a statement in favor Medical Problems of Performing Artists, 14, pp. 117 - 121.

Lewinsohn, P.M., Gotlib, I. H., Lewinsohn, M., Seeley, J. R., \& Allen, N. B. (1998). Gender differences in anxiety disorders and anxiety symptoms in adolescents. Journal of Abnormal Psychology, 107, 109-117. WwW

Maroon, M. T. J. (2003). Potential contributors to performance anxiety among middle school students performing at solo and ensemble contest. Dissertation Abstracts International, 64, 437.

Merritt, L., Richards, A., \& Davis, P. (2001). Performance anxiety: Loss of the spoken edge. Journal of Voice, 15, 257-269. WWW

Mor, S., Day, H. I., Flett, G. L., \& Hewitt, P. L. (1995). Perfectionism, control, and components of per- 
formance anxiety in professional artists. Cognitive Therapy and Research, 19, 207-225.

Nagel, J. J. (1987). An examination of commitment to career in music: Implications for alienation from vocational choice. Dissertation Abstracts International 42, 1154-1155.

Osborne, M. S., \& Franklin, J. (2002). Cognitive processes in music performance anxiety. Australian Journal of Psychology, 54, 86-93.

Osborne, M. S., \& Kenny, D. T. (2005a). Development and validation of a music performance anxiety inventory for gifted adolescent musicians. Journal of Anxiety Disorders, 19, 7, 725-751. [wWw

Osborne, M.S. \& Kenny, D. T. (2005b). The role of sensitizing experiences in the experience of music performance anxiety. Performance Matters! International conference organized by CIPEM, ESCOM, and SEMPRE, Porto, Portugal, 14-17 September 2005.

Osborne, M. S., Kenny, D.T. \& Holsomback, R. (2005). Assessment of music performance anxiety in late childhood: A validation study of the Music Performance Anxiety Inventory for Adolescents (MPAI-A). International Journal of Stress Management, 12, 312-330.

Passer, M. W. (1983). Fear of failure, fear of evaluation, perceived competence, and self-esteem in competitive-trait-anxious children. Journal of Sport Psychology 5, 172-188.

Piaget, J. (1970). Piaget's theory. In P. H. Mussen (Ed.), Carmichael's manual of child psychology. New York: Wiley.

Ryan, C. (1998). Exploring musical performance anxiety in children. Medical Problems of Performing Artists, 13, 83-88.

Ryan, C. (1999). Musical performance anxiety: Are junior high band students affected? Opus 41, 8-9.

Ryan, C., (2004). Gender differences in children's experience of musical performance anxiety. Psychology of Music 32, 89-103.

Ryan, C. (2005) Experience of musical performance anxiety in elementary school children. In D.T Kenny (Guest Editor) (2005). Special edition: Performance anxiety in human endeavor. International Journal of Stress Management.

Ryan, C.A. (2003). A study of the differential responses of male and female children to musical performance anxiety. Dissertation Abstracts International, 63, 2487.

Salmon, P. (1990). A psychological perspective on musical performance anxiety: a review of the literature. Medical Problems of Performing Artists, 5 , 2-11.
Scanlan, T. K., \& Lewthwaite, R. (1984). Social psychological aspects of competition for male youth sport participants: I. Predictors of competitive stress. Journal of Sport Psychology, 6, 208-226.

Simon, J. A., \& Martens, R. (1979). Children's anxiety in sport and nonsport evaluative activities. Journal of Sport Psychology, 1, 160-169.

Sinden, L. M. (1999). Music performance anxiety: Contributions of perfectionism, coping style, self-efficacy, and self-esteem. Dissertation Abstracts International, 60, 0590.

Smith, R. E., Smoll, F.L., \& Barnett, N.P. (1995). Reduction of children's sport anxiety through social support and stress-reduction training for coaches. Journal of Applied Developmental Psychology, 16, 125-142.

Spielberger, C. (1983). Manual for the State-Trait Anxiety Inventory. Palo Alto, CA: Consulting Psychologists.

Steiner, A. (1998). The relationship between performance anxiety and narcissism in musicians. Dissertation Abstracts International, 59, 1869.

Tamborrino, R. A. (2001). An examination of performance anxiety associated with solo performance of college-level music majors. Dissertation Abstracts International, 62, 1636.

Terry, P., Coakley, L., \& Karageorghis, C. (1995). Effects of intervention upon precompetition state anxiety in elite junior tennis players: The relevance of the matching hypothesis. Perceptual and Motor Skills, 81, 287-296. WwW

Wilson, G. D. (2002). Psychology for performing artists (2nd ed.). London, UK: Whurr.

Wolfe, M. L. (1989). Correlates of adaptive and maladaptive musical performance anxiety. Medical Problems of Performing Artists, 4, 49-56.

Zatz, S., \&Chassin, L. (1985). Cognitions of test-anxious children under naturalistic test-taking conditions. Journal of Consulting and Clinical Psychology 53, 393-401.

Zinn, M. L. and McCain, C and Zinn, M. A. (2000) Music Performance Anxiety and the High Risk Model of Threat Perception Medical Problems of Performing Artists, 15, pp. $65-71$. 